\title{
Ibn Sina on Substances and Accidents
}

\author{
ERWIN TEGTMEIER, MANNHEIM
}

There was a vivid and influential dialogue of Western philosophy with Ibn Sina in the Middle Ages; but there can be also a fruitful dialogue of Western philosophy with him today. I do not approach Ibn Sina as a scholar but as a metaphysician and admirer. I was attracted to him because of similarities between our ontologies, and have learned a lot from him. Moreover, I think that only metaphysicians can fully appreciate Ibn Sina's achievements and his greatness.

A crucial move for Ibn Sina's theory of substance is his distinction between existence and actual existence. ${ }^{1}$ Ibn Sina's concept of existence is really new. The concept of actual existence or actuality (energeia) is to be found already in Aristotle. Aristotle equates being actual with being a substance (ousia) and with having a substantial form (eidos) which plays the role of essence ( $t i$ en einai). Insofar as a substance has and is a substantial form it is actual. Prime matter has no actuality according to Aristotle but merely potentiality. Indeed, Aristotle takes prime matter to have no being whatsoever and to be unknowable. Nevertheless, he draws on it in his ontological analysis. Hence it should be granted ontological status. That argument may have been one of the reasons which led Ibn Sina to discern existence in the sense of having ontological status or simply being there. At any rate it allows him to give ontological status to prime matter, although he takes it to have nothing but potentiality and to lack individuation. Like Aristotle, Ibn Sina holds that prime matter is not a "this there" (tode ti), i.e., a located particular, and also that prime matter without essential form is undifferentiated (unindividuated), i.e., that without essential form there is only one prime matter. Nevertheless, Ibn Sina's granting ontological status (existence) to prime matter is enough to make the actual substance a clear complex. Aristotle takes it to be basically simple.

Ibn Sina's upgrading of prime matter goes so far as to categorise it as a

\footnotetext{
1 Ibn Sina 1960, 45ff.
} 
substance though not a substance with actuality, not an actual substance. An actual substance is always a composition of prime matter and essential form. With actual substance turning into a composition, into a complex, the problem of unity arises which is the question of how the constituents of the complex are held together.

Ibn Sina points out that matter cannot be free from an essential form, that the former needs the latter to be actual, and that essential forms do not exist separately from matter. ${ }^{2}$ However, that mutual dependence does not seem to Ibn Sina sufficient to ground the togetherness of matter and form in an actual substance. He understands the problem of the unity of the actual substance as the task of showing that the matter and form that come together are necessarily together. Ibn Sina argues that the potentiality of prime matter to receive essential forms does not make the connection with the form it has necessary, since it is a potentiality, and ready to receive any form. That implies that it could have received another form. He argues that this is shown by the occurrence of substantial change, i.e., change of essential form. Correspondingly, although the essential form cannot exist separately from any prime matter, it could be the essence of another prime matter. Ibn Sina also argues against there being a relation between matter and form in the Aristotelian sense, i. e., against the assumption that there are the relational accidents 'being the essence of matter $m$ ' and 'being the matter of essence $e$ '. These relational accidents would entail each other and make matter and form necessarily related entities. The main conclusion of Ibn Sina's deliberations concerning the unity of the complex of matter and form is that it is of itself not necessary but contingent and that its unity must be caused from outside. Thus, Ibn Sina grounds the connection between matter and form on a causal accident and holds that with this accident the connection becomes necessary.

I agree with Ibn Sina that the possession of essential properties is not necessary but contingent. Instead of "contingent" one sometimes says "factual". In accordance with this use I ground the possession of essential properties on facts, although I ground also necessity on facts, namely general facts. The possession of properties is founded on atomic facts. And I concur with Ibn Sina that taking into account the cause of the actual

2 Ibid. 119ff. 
substance will lead to the conclusion that it is necessary.

However, I would argue that the problem of the unity of the actual substance and the problem of the unity of complexes in general has to be distinguished from the question: "What caused the complex?"(in the customary sense), though many contemporary philosophers as well as philosophers of the idealistic tradition in the wide sense, confuse the two questions. In my ontological analysis there is a marked difference. The connection between matter and essential form is based, as was mentioned already, on a certain fact, namely the fact that the matter has that form, while the cause of that fact is another fact, e.g., the fact that a certain chicken egg had a certain temperature at a certain period of time is the cause of the prime matter of the resulting chicken having the essential form of a chicken. This genetic explanation is quite different from the ontological explanation of the structure of the actual chicken as a composition of matter and form.

Concerning the categorial structure of the actual substance I disagree with Ibn Sina. From the assumption that the essence of a substance can change, which I share with him, I draw the conclusion that it must be external, i.e., that the essential form is connected with the substance only by a certain fact. It is the fact that the respective prime matter has the respective essential form.

This further implies that the prime matter is the substance by being that which has the essential, the substantial form. Ibn Sina, as was mentioned already, categorises prime matter as a substance but continues to consider the actual substance, i.e., the complex of prime matter and essential form, as the substance proper. But with respect to prime matter he makes another important move. Not only does he realise that matter has to have ontological status, as was mentioned already, but he also sees that there must be some entity which makes prime matter prime matter. ${ }^{3}$ That entity he calls material essence, which is distinguished clearly from the corporal essence, which makes an actual substance a corporal (material) rather than a mental substance.

Instead of "prime matter" I name the corresponding category "individual". What makes an individual an individual? Its individuality.

3 Ibid. 133. 
One could characterise the individuality of an individual as its "categorial essence" and distinguish "categorial" and "substantial" essence.

I claim that there is no categorial change and that the connection between an individual and its individuality is closer than that between it and its substantial and other properties. The latter are connected by facts; the categorial properties not. The categorial properties are internal, one could say, the substantial and other properties external. This distinction mirrors the distinction in Ibn Sina's ontology between the actual substance, which is complex, and prime matter, which is simple. Individuals are simple only after a fashion. The individuality is not a constituent of the individual (only facts have constituents), but it is present at the individual (analogous to the form in a literal sense of shape which is present in a body without being a spatial part of it).

Like prime matter in the Aristotelian tradition individuals are substrata. They are the bearers of the substantial properties. But in contrast to the Aristotelian tradition, they also bear all other first order properties. According to Ibn Sina's ontology prime matter plays the role of substratum by forming a complex with substantial properties (essence). The other properties (the accidents) are added by inhering in the complex. Ibn Sina explains that the inherence does not imply being part of the actual substance.

We have seen that Ibn Sina upgrades prime matter considerably by categorising it as a substance and by giving it an essence of its own. But he did not go so far as Aquinas to localise it and give it the task of individuator. However, Aquinas assimilates matter to form and does not continue Ibn Sina's upgrading of matter. Ibn Sina held the view that it is the essential form that individuates matter and, as far as bodily substances are concerned, that lends them extendedness and a place in space. The individuals of my own ontology are localised and are also individuators. However, they individuate only themselves and only indirectly the facts of which they are constituents. It has to be added that like Suarez, I subscribe to the principle that each entity (at least each simple entity) has to individuate itself. That implies that there is a problem of individuation not only for substances, for concrete things, but also for essences and accidents, it implies that individuation is a problem for all categories. It implies also that the search for a principle of individuation, i.e., for an 
entity other than the entity to be individuated, is misguided as far as simple entities are concerned.

Like the Scholastics, I advocate the view that diversity (i.e., the ontological ground of individuation) is a transcendental. That implies mainly two contentions: (1) that diversity is not an entity (res), and that there is no relation of diversity, and (2) that diversity transcends the category boundaries, that it is not restricted to certain categories but occurs in all categories and that it is therefore equivalent to-though, of course, not identical with - being an existent, with existing. We have explained in accordance with Ibn Sina that existing is the same as having ontological status and not with being an actual substance, as in Aristotle. Now, the doctrine of transcendentals as sketched implies that what has ontological status is diverse from every other existent and is thus individuated. Accepting that doctrine. one could challenge Ibn Sina by pointing out that he cannot grant ontological status to prime matter without granting it also individuation.

Why is Ibn Sina convinced that prime matter is of itself not individuated and that it has to be individuated by essential form? For two reasons, I think: the first is that he thinks of individuation in terms of differentiation, i.e., diversity is reduced to qualitative difference). That was standard until Suarez, and underlies also the so-called Leibniz-Russell Definition of identity or rather the logically equivalent definition of nonidentity (diversity). It goes well with Aristotle's view, which Ibn Sina adopts, that prime matter is a substratum (hypokeimenon), a bearer of the substantial form and that the relation between matter and form is predicative. Matter has form. Hence there is a similarity between the relation of matter-form and substance-accident. Aristotle considers the substance also as the substratum of its accidents.

Individuation by differentiation is dubious on two accounts. Firstly, it leads to an infinite regress, since it grounds the diversity of property bearers on the diversity of properties and gives rise to the task of grounding the diversity of the properties, etc. Such a regress arises with all principles of individuation, i.e., it arises always if entities are individuated by other entities, not only if the other entities are properties. Secondly, one may object to individuation of a constituent of a complex by another constituent. Clearly, a complex is a complex only by virtue if its 
constituents being diverse from each other. The circumstance that there are more than one constituent presupposes that they are diverse. One constituent cannot make another constituent another constituent because for that it has to be already another constituent.

An additional consideration can be brought forward against Ibn Sina's individuation of the complex actual substance by one of its constituents. It is plausible - though not inevitable - to base the individuation of a complex entitiy on the individuation of its constituents. While simple entities individuate themselves, the individuation of complex entities is derived, according to this view, from the individuation of their constituents. With regard to that, the individuation of actual substances as complexes seems somehow difficult in Ibn Sina's ontology. Clearly, the substantial form does not individuate the actual substance. This is not because it is general. Ibn Sina takes it to be as such neither general nor particular. Only in an actual substance and together with matter does it become particular. Hence one can say that neither matter nor substantial form are individuated independently of an actual substance. That seems to make derived individuation of the actual substance lose its ground. One wonders how individuation can be based on what is not individuated itself. And one can hardly make sense of Ibn Sina's machinery of individuation.

Aquinas seems to be better off at this point. He grounds the individuation of the actual substance on the spatio-temporally specified or determined substantial form, i.e., on the substantial form with a designated matter. This is clearer than what Ibn Sina offers. And it is clearly individuation by differentiation.

I should mention that Ibn Sina gives a straightforward and simple answer to the question: "What individuates actual substances?", namely: "their accidents". ${ }^{4}$ The answer does not seem to me satisfactory because the problem of individuation, even of complexes, is a fundamental ontological problem for each kind of entity. Therefore, it cannot be solved by entities which are added (by symbebekota). However, the answer would be adequate if the question were not: "What grounds the diversity between actual substances?" but "By what marks do we recognise actual substances?". And the attempt to replace the fundamental theoretical

4 Ibid. 140. 
problem of individuation by the practical problem of reidentification is common in analytical philosophy, from Strawson on. But it certainly is not in accordance with Ibn Sina's metaphysics. Ibn Sina is the opposite of an anti-metaphysician such as Ghazali or Wittgenstein.

Now, there are interpretations according to which existence is Ibn Sina's principle of individuation. ${ }^{5}$ For these one has to take into account Ibn Sina's distinction between existence and actual existence. It gives rise to the question of whether existence or actual existence is the principle of individuation. In answering, existence has to be excluded since prime matter is assumed to exist but not to be individuated. Surely, something cannot have the principle of individuation and not be individuated. What about actual existence as a principle of individuation? As was mentioned already, Ibn Sina holds that the actualisation by virtue of the essential form particularises prime matter in the first place. Particularisation (turning an entity into a particular) and individuation (making it diverse from every other entity) are closely related. Do they coincide in this case? One may wonder whether the conception of particularisation is clear, and doubt that an entity which is not a particular can be turned into a particular. Aquinas explains how an essential form furnishes a principle of individuation, namely by maximally specifying the form: a human body, e. g., is individuated by specifying human flesh in general into this flesh. The maximally specified essential form then is what grounds the diversity of this human body from all other entities. And since the essential form brings actual existence to the concrete substance there is a close connection between actual existence and individuation. This connection is particularly close since a maximally specific essential form brings individuation only by making a substance actual. Hence, one could consider actual existence as the cause of individuation. Nevertheless, while the maximally specific essential form is able to ground the diversity of a concrete substance from all other concrete substances, actual existence as such is not. A particular substantial form lends actual existence to a substance but it is not the same as actual existence.

The main motive for attributing to Ibn Sina the view that existence is the principle of individuation is to find in him a principle of individuation

5 See the paper by M. Shomali in this volume. 
which is applicable also to God. The individuation of God is without doubt a difficult problem. But it can be solved as in Aquinas by considering him an exceptional case, which is very much in accordance with monotheistic theology.

\section{REFERENCES}

Afnan, S.M. 1980 Avicenna. His Life and Works, Westport: Greenwood Press.

Avicenna 1960 Das Buch der Genesung der Seele, ed. M. Horten, Frankfurt: Olms.

Tegtmeier, E. 1992 Grundzüge einer kategorialen Ontologie. Dinge, Eigenschaften, Beziehungen, Sachverhalte, Freiburg/München: Alber.

Weinberg, J.R. 1964 A Short History of Medieval Philosophy, Princeton: Princeton University Press.

Verbeke, G. 1983 Avicenna. Grundleger einer neuen Metaphysik, Opladen:

Westdeutscher Verlag. 